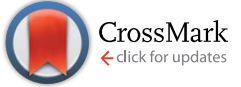

Cite this: RSC Adv., 2017, 7, 2426

\title{
Fine-tuning of multiple upconversion emissions by controlling the crystal phase and morphology between $\mathrm{GdF}_{3}: \mathrm{Yb}^{3+}, \mathrm{Tm}^{3+}$ and GdOF: $\mathrm{Yb}^{3+}, \mathrm{Tm}^{3+}$ nanocrystals
}

\author{
Yongsheng Zhu, ${ }^{\text {ab }}$ Dongqin $\mathrm{Bi}^{\text {a }}$ Huiqiao Wang, ${ }^{a}$ Yinhua Wang, ${ }^{a}$ Xiumei $\mathrm{Xu}{ }^{a}$ \\ Zhiwen $\mathrm{Lu}^{\mathrm{a}}$ and Wen $\mathrm{Xu} \mathrm{u}^{\star \mathrm{b}}$
}

\begin{abstract}
Fine-tuning of multi-color emission characteristics of upconversion lanthanide-ion-doped nanocrystals is of high importance for 3-D color displays, multi-color bio-imaging, and multiplexed cellular labeling. Here, we report a strategy enabling crystal phase transition and morphology transformation between $\mathrm{GdF}_{3}: \mathrm{Yb}^{3+}, \mathrm{Tm}^{3+}$ and GdOF: $\mathrm{Yb}^{3+}, \mathrm{Tm}^{3+}$ nanocrystals for fine-tuning of upconversion multi-color emissions. By controlling the ratio between oleylamine (OM)/octadecene (ODE), the orthorhombic phase of rhombic nanoplates $\left(\mathrm{GdF}_{3}: \mathrm{Yb}^{3+}, \mathrm{Tm}^{3+}\right)$ was transformed to the cubic phase of nanospheres $\left(\mathrm{GdOF}: \mathrm{Yb}^{3+}, \mathrm{Tm}^{3+}\right)$, along with their upconversion color change from blue to red. Broadband upconversion emission was observed from GdOF:Yb ${ }^{3+}, \mathrm{Tm}^{3+}$ nanocrystals at a high excitation power, which is expected to originate from oxygen defects. Multi-color upconversion nanocrystals providing broadband emission are expected to find their applications in broad band multi-color biomolecular imaging requiring a high imaging resolution.
\end{abstract}

Received 19th November 2016
Accepted 12th December 2016

DOI: $10.1039 / \mathrm{c} 6 \mathrm{ra} 27024 \mathrm{~g}$

www.rsc.org/advances

\section{Introduction}

Upconversion (UC) is an anti-stokes type emission process in which the sequential absorption of two or more longer wavelength photons leads to emission of one shorter wavelength photon. The pioneering work of lanthanide-ion doped UC materials was reported by Auzel et al., including the $4 \mathrm{f}-4 \mathrm{f}$ electronic structure, spectra, and population mechanism. ${ }^{\mathbf{1} 2}$ Recently, rare-earth (RE) doped upconversion nanocrystals (UCNCs) have been widely used in 3-D color displays, ${ }^{3}$ multicolor biomolecular imaging, ${ }^{4}$ ratiometric sensors, ${ }^{5}$ solar cells, ${ }^{6}$ and so on, ${ }^{7,8}$ due to their large anti-Stokes shift, low autofluorescence, high tissue penetration depth, sharp emission lines, and long excited-state lifetimes. ${ }^{9-11}$ However, each RE activator ion in UCNCs generally exhibits a set of inherent emission peaks only because of its inherent energy level. ${ }^{\mathbf{1 2}}$ For wider applications in imaging, the multi-color emissions of REdoped UCNCs should be finely tuned. Up to date, there have been a number of approaches for the purpose, e.g. tailoring REdoping concentration, changing the morphology, phase transition, and shape of UCNCs, controlling the laser pulse width, and utilizing the energy migration in core-shell UCNCs. ${ }^{13-19}$

${ }^{a}$ College of Physics and Electronic Engineering, College of Chemistry and Pharmaceutical Engineering, Nanyang Normal University, Nanyang 473061, China

${ }^{b}$ State Key Laboratory on Integrated Optoelectronics, College of Electronic Science and Engineering, Jilin University, 2699 Qianjin Street, Changchun 130012, China. E-mail: wen_xu09@163.com
Controlling UCNCs' crystal phase and morphology is one of the promising ways for accurately tuning UC emissions properties..$^{20,21}$

Among RE-doped UCNCs, RE-doped fluorides and oxyfluorides NCs got more attention due to their high ionicity, low phonon energy, and high chemical and thermal stability. ${ }^{22,23}$ Especially, gadolinium based UCNCs can be used for multimodal imaging (upconversion luminescent imaging and magnetic resonance imaging at a time), because $\mathrm{Gd}^{3+}$ can serve as a positive contrast agent for magnetic resonance imaging. ${ }^{\mathbf{2 4 - 2 6}}$ Nowadays, RE-ions doped $\mathrm{GdF}_{3}$ and GdOF NCs with various shapes can be synthesized by several techniques, such as the solid state reaction, the sol-gel method, the thermolysis method and the hydrothermal method. ${ }^{27-30}$ Up to date, to our best knowledge, the fine-tuning of multi-color UC emissions between RE-ions doped $\mathrm{GdF}_{3}$ and GdOF NCs by controlling the crystal structure and morphology evolution has not been reported.

In this work, we present the crystal phase and morphology evolution between $\mathrm{GdF}_{3}: \mathrm{Yb}^{3+}, \mathrm{Tm}^{3+}$ and GdOF: $\mathrm{Yb}^{3+}, \mathrm{Tm}^{3+} \mathrm{NCs}$ by using the thermolysis of $\mathrm{RE}\left(\mathrm{CF}_{3} \mathrm{COO}\right)_{3}$ under the cooperative effect of oleic acid (OA), oleylamine (OM), and octadecene (ODE). The preparation method develop a new route towards a general synthesis of high-quality $\mathrm{GdF}_{3}$ and GdOF nanocrystals, which have advantages of high crystallinity, uniform size, high luminescence efficiency. The shape and phase structure of $\mathrm{GdF}_{3}$ and GdOF NCs can be controlled between 
orthorhombic phase with rhombic nanoplates $\left(\mathrm{GdF}_{3}\right)$ and the cubic phase with nanospheres (GdOF) by just adjusting the ratio between OM and ODE. Meanwhile, UCL color also changes from blue to red with the crystal phase evolution from the orthorhombic $\left(\mathrm{GdF}_{3}: \mathrm{Yb}^{3+}, \mathrm{Tm}^{3+}\right)$ to the cubic phase $\left(\mathrm{GdOF}: \mathrm{Yb}^{3+}, \mathrm{Tm}^{3+}\right)$. Interestingly, UC broadband emissions are observed in GdOF: $\mathrm{Yb}^{3+}, \mathrm{Tm}^{3+} \mathrm{NCs}$ at a high power excitation density. The mechanism of color alternating and UC broadband in $\mathrm{GdF}_{3}: \mathrm{Yb}^{3+}, \mathrm{Tm}^{3+}$ and GdOF: $\mathrm{Yb}^{3+}, \mathrm{Tm}^{3+} \mathrm{NCs}$, and UC broadband emissions in GdOF: $\mathrm{Yb}^{3+}, \mathrm{Tm}^{3+} \mathrm{NCs}$ will be discussed in details.

\section{Experimental section}

\subsection{Sample preparation}

All the chemicals were analytical grade and used as received without further purification. All the lanthanide oxides were purchased from the National Engineering Research Centre of Rare Earth Metallurgy and Function Materials. First, $\mathrm{Gd}\left(\mathrm{CF}_{3^{-}}\right.$ $\mathrm{COO})_{3}, \mathrm{Yb}\left(\mathrm{CF}_{3} \mathrm{COO}\right)_{3}$, and $\mathrm{Tm}\left(\mathrm{CF}_{3} \mathrm{COO}\right)_{3}$ hydrate $(1 \mathrm{mmol})^{31}$ were added into the oleic acid, oleylamine and octadecene mixed solution, the doped concentration of $\mathrm{Yb}^{3+}$ and $\mathrm{Tm}^{3+}$ ions was $15 \mathrm{~mol} \%$ and $1 \mathrm{~mol} \%$, respectively. In the reaction system, the total amount of oleic acid, oleylamine and octadecene was $20 \mathrm{ml}$, and oleic acid was fixed for $10 \mathrm{ml}$, the four different OM/ ODE ratios of $4: 1,3: 2,2: 3$ and $1: 4$ were selected. And the solution was heated to $120{ }^{\circ} \mathrm{C}$ to remove water with vigorous magnetic stirring under vacuum for 40 minutes until forming a transparent solution. Then the mixed solution was heated to $320{ }^{\circ} \mathrm{C}$ at a heating rate of $10{ }^{\circ} \mathrm{C} \mathrm{min}^{-1}$ and kept for 1 hour under $\mathrm{N}_{2}$ atmosphere, and thus a light-yellow colloidal solution was obtained, the yields of all the obtained nanocrystals were $30-40 \%$. To selectively obtain $\mathrm{GdF}_{3}$ or GdOF NCs, the fluorination of the $\mathrm{Gd}-\mathrm{O}$ bond to the $\mathrm{Gd}-\mathrm{F}$ bond at the nucleation stage was controlled by finely tuning the ratio of OM/ODE. ${ }^{32}$ After the solution was cooled naturally, an excess of ethanol was added and the resulting mixture was centrifugally separated. The products were collected and washed with ethanol for three times, and followed by oven-dried at $60{ }^{\circ} \mathrm{C}$.

\subsection{Characterization and measurements}

The size and morphology of UCNCs were determined with a Hitachi H-8100IV transmission electron microscope (TEM) under an acceleration voltage of $200 \mathrm{kV}$. All the samples were dispersed in the cyclohexane and dropped on the surface of a copper grid for tests. Powder X-ray diffraction (XRD) measurements were performed on a Rigaku D/max-rA power diffractometer diffractometer using $\mathrm{Cu} \mathrm{K} \alpha$ radiation $(\lambda) 1.54178$ $\AA$ at a scanning rate of $1^{\circ} \mathrm{min}^{-1}$ in the $2 \theta$ ranging from $10^{\circ}$ to $70^{\circ}$. A photomultiplier combined with a monochromator was used for signal collection from $400 \mathrm{~nm}$ to $850 \mathrm{~nm}$. To investigate the steady-state spectra, a continuous $980 \mathrm{~nm}$ diode laser was used to pump the samples. The luminescent dynamics of $\mathrm{Tm}^{3+}$ ions were investigated by a laser-system consisting of a Nd:YAG pumping laser (1064 nm), a third-order harmonic-generator (355 $\mathrm{nm}$ ) and a tunable optical parameter oscillator (OPO,
Continuum Precision II 8000). The laser has pulse duration of $10 \mathrm{~ns}$, repetition frequency of $10 \mathrm{~Hz}$ and line width of $4-7 \mathrm{~cm}^{-1}$. The brightness of the UC broadband was measured by a PR650 spectrometer.

\section{Results and discussion}

\subsection{Size, morphology and crystal phase transformation between $\mathrm{GdF}_{3}: \mathrm{Yb}^{3+}, \mathrm{Tm}^{3+}$ and GdOF: $\mathrm{Yb}^{3+}, \mathrm{Tm}^{3+} \mathrm{NCs}$}

Fig. 1(a-d) show the morphology of UCNCs prepared at different OM/ODE ratios of $4: 1,3: 2,2: 3$ and $1: 4$. First, UCNCs are in uniform, monodisperse and rhombic shapes (Fig. 1(a and b)). The average side lengths of these NCs are 15.4 and $13.6 \mathrm{~nm}$ with a standard deviation of $1.0 \mathrm{~nm}$ (see Fig. 1(i and j)). The corresponding HR-TEM images of the lattice fringes with $d$-spacing of $0.195 \mathrm{~nm}$ and $0.20 \mathrm{~nm}$ are observed (Fig. 1(e and f)), which is in good agreement with the lattice spacing of the (301) planes of orthorhombic $\mathrm{GdF}_{3}$ (0.1961 nm, JCPDS: 12-0788). When the OM/ODE ratios was changed to $2: 3$ and $1: 4$, the UCNCs were transformed into spherical NCs with the smaller sizes of to 2.5 and $2.0 \mathrm{~nm}$ (Fig. 1(c, d, k and l)). Their lattice spacing was determined to $0.326 \mathrm{~nm}$ and $0.324 \mathrm{~nm}$ (Fig. 1 ( $\mathrm{g}$ and $\mathrm{h}$ )), which is according with the lattice spacing of the (012) planes of cubic GdOF (0.3161 nm, JCPDS: 50-0569). General trend of morphology and phases transition from rhombic shapes $\left(\mathrm{GdF}_{3}\right)$ to spherical shapes (GdOF) as a function of OM/ODE ratios is shown in Fig. 2(a). In addition, the space structure of orthorhombic $\mathrm{GdF}_{3}$ and tetragonal GdOF are simulated, which belongs to the orthorhombic crystal system $(a=6.570 \AA$ A, $b=$ $6.984 \AA, c=4.393 \AA)$ and the cubic crystal system $(a=5.363 \AA$, $b=5.363 \AA, c=5.363 \AA$ ), respectively, as shown in Fig. 2(b and c). It should be noted that the $\mathrm{Gd}^{3+}-\mathrm{Gd}^{3+}$ distance in orthorhombic $\mathrm{GdF}_{3} \mathrm{NCs}$ are $3.884 \AA$ and $4.447 \AA$, which is longer than that of $3.792 \AA$ in cubic GdOF NCs. ${ }^{33-36}$ The crystal structure's evolution was further monitored by tracking the changes in the UCNC's XRD patterns, as shown in Fig. 2(d and e). All the diffraction peaks can be exclusively indexed to orthorhombic $\mathrm{GdF}_{3}$ (Fig. 2(d)) and cubic GdOF (Fig. 2(e)), the peaks confirms the presence of highly crystalline $\mathrm{GdF}_{3}$ and GdOF NCs without impurity phases. In other words, the morphology and phase transforming between $\mathrm{GdF}_{3}$ and GdOF can be simultaneously controlled by adjusting the ratios between OM and ODE. The two-dimensional growth of the $\mathrm{GdF}_{3}$ rhombic nanoplates and the zero-dimensional growth of the GdOF spherical NCs are likely due to the selective adsorption of the capping ligands on specific crystal planes of NCs. The phase evolution between $\mathrm{GdF}_{3}$ and GdOF are more likely due to the different fluorination of the $\mathrm{Gd}-\mathrm{O}$ bond to the $\mathrm{Gd}-\mathrm{F}$ bond at the nucleation stage in different ratios of OM/ODE. ${ }^{37}$ The size, shape, and phase of UCNCs can also be affected by organic surfactant, reaction solvent, reaction temperature and the ionic radius of lanthanide ions. ${ }^{38,39}$ It should be noted most of NCs still retain uniformity and monodispersity after the morphology and phase transformation. And a small degree of agglomeration consisting of two or three NCs is happened (Fig. 1 (c and d)). Such agglomeration is usually observed in small NCs, due to the high activity of small NCs. 

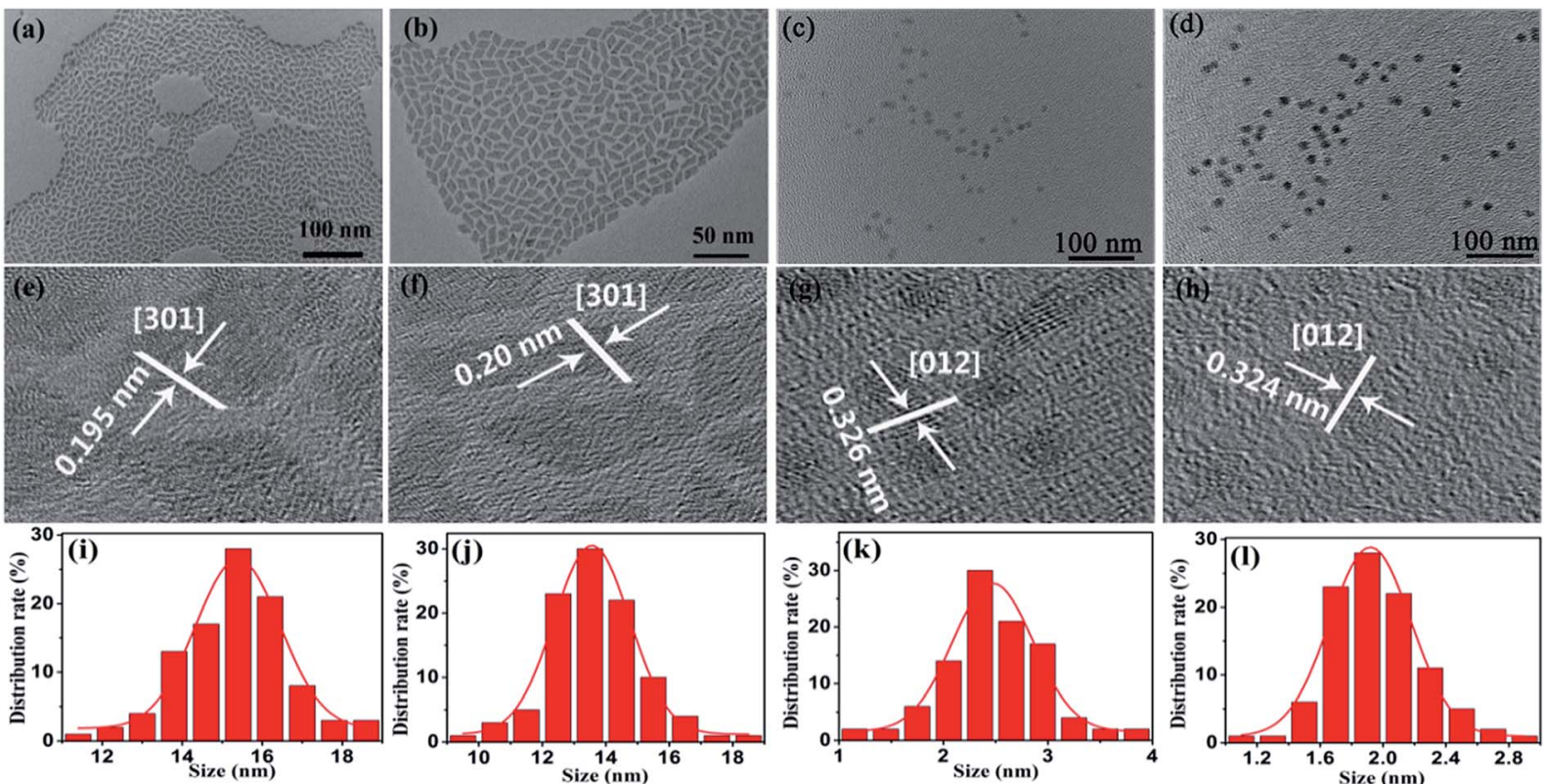

Fig. 1 (a-d) TEM images, (e-h) HR-TEM images, and (i-l) size distribution of GdF $\mathrm{Yb}^{3+}, \mathrm{Tm}^{3+}$ and GdOF:Yb ${ }^{3+}, \mathrm{Tm}^{3+} \mathrm{NCs}^{3 y n t h e s i z e d ~ a t ~ O M / O D E}$ ratios of $4: 1,3: 2,2: 3$ and $1: 4$, respectively.

(a)

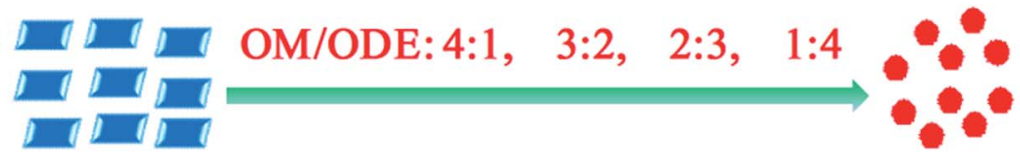

(b)
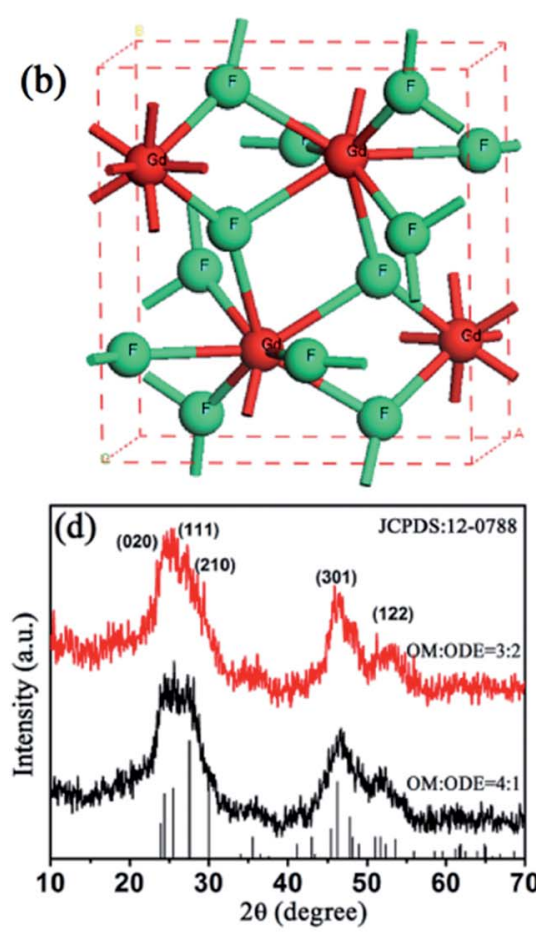

(c)
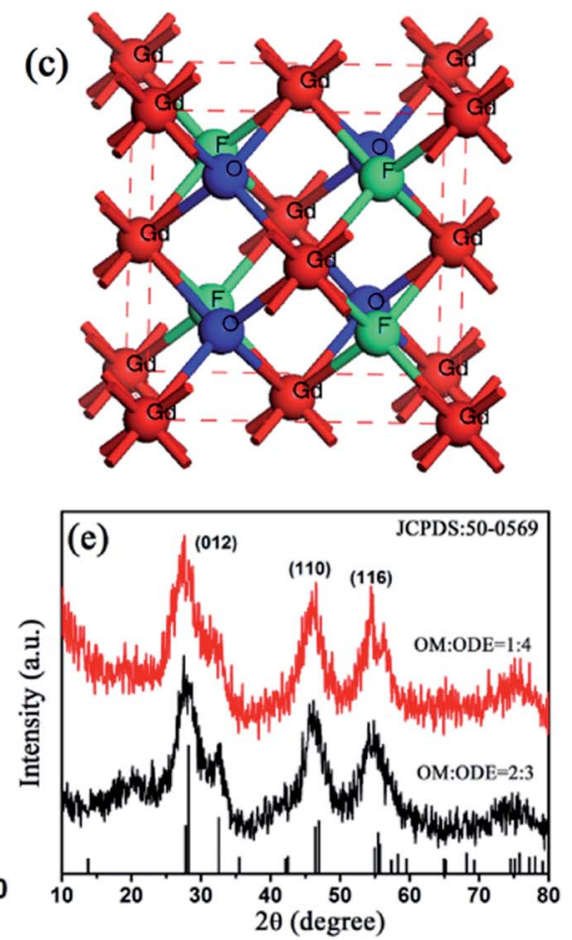

Fig. 2 (a) Schematic of morphology transition from rhombic shapes $\left(G_{d F}\right)$ to spherical shapes (GdOF) as a function of OM/ODE ratios; (b and c) schematic of crystal phase structure orthorhombic GdF 3 and cubic GdOF; (d and e) XRD patterns of GdF $\mathrm{Yb}^{3+}, \mathrm{Tm}^{3+} \mathrm{and} \mathrm{GdOF}^{\mathrm{Yab}}{ }^{3+}, \mathrm{Tm}^{3+} \mathrm{NCs}$ prepared at OM/ODE ratios of $4: 1,3: 2,2: 3$ and $1: 4$, respectively. 
3.2. Upconversion luminescence depending on defect state, crystal phase and size

As known, the UCL properties of the RE-doped NCs strongly depend on their size, crystal structure, phonon energy, and defect states. In order to reveal the effect of the above elements on the UCL, the power-dependent spectra of $\mathrm{GdF}_{3}: \mathrm{Yb}^{3+}, \mathrm{Tm}^{3+}$ and GdOF: $\mathrm{Yb}^{3+}, \mathrm{Tm}^{3+}$ NCs are measured (see in Fig. 3(a-d)). As shown in Fig. 3(a and b), the typical UC multi-color emission of $\mathrm{Tm}^{3+}$ ions can be distinguished in $\mathrm{GdF}_{3}: \mathrm{Yb}^{3+}, \mathrm{Tm}^{3+} \mathrm{NCs}$, assigned to the ${ }^{1} \mathrm{D}_{2}-{ }^{3} \mathrm{H}_{6}(368 \mathrm{~nm}),{ }^{1} \mathrm{D}_{2}-{ }^{3} \mathrm{~F}_{4}(456 \mathrm{~nm}),{ }^{1} \mathrm{G}_{4}-{ }^{3} \mathrm{H}_{6}(480 \mathrm{~nm})$, ${ }^{1} \mathrm{G}_{4}-{ }^{3} \mathrm{~F}_{4}(652 \mathrm{~nm}),{ }^{3} \mathrm{~F}_{3}-{ }^{3} \mathrm{H}_{6}(700 \mathrm{~nm})$ and ${ }^{3} \mathrm{H}_{4}-{ }^{3} \mathrm{H}_{6}(800 \mathrm{~nm})$ transitions, respectively. It should be noted that the dominant UC emission line locates in the blue region, centering at $480 \mathrm{~nm}$. Interestingly, the luminescence intensity ratio of ${ }^{1} \mathrm{D}_{2}-{ }^{3} \mathrm{H}_{6}+{ }^{3} \mathrm{~F}_{4}$ to ${ }^{1} \mathrm{G}_{4}-{ }^{3} \mathrm{H}_{6}$ transitions decreases with the increase of excitation power density in $\mathrm{GdF}_{3}: \mathrm{Yb}^{3+}, \mathrm{Tm}^{3+} \mathrm{NCs}$, which is opposite to the result observed in oxide host, such as $\mathrm{NaGd}\left(\mathrm{WO}_{4}\right)_{2}: \mathrm{Yb}^{3+}, \mathrm{Tm}^{3+}$ $\mathrm{NCs},{ }^{40} \mathrm{Tm}^{3+} / \mathrm{Yb}^{3+}$ codoped water-free low silica calcium aluminosilicate glasses. ${ }^{41}$ This phenomenon can be attributed to the improved cross relaxation process of ${ }^{1} \mathrm{D}_{2}+{ }^{1} \mathrm{G}_{4}-{ }^{3} \mathrm{~F}_{3}+{ }^{1} \mathrm{G}_{4}$ with the increasing excitation power density, which can effectively increase the population of the ${ }^{1} \mathrm{G}_{4}$ energy level. ${ }^{42}$

However, as the crystal structure transforms from $\mathrm{GdF}_{3}$ (Fig. 3(a and b)) to GdOF (Fig. 3(c and d)), the UC color changes from blue to red and the dominant emission in GdO$\mathrm{F}: \mathrm{Yb}^{3+}, \mathrm{Tm}^{3+} \mathrm{NCs}$ is assigned to ${ }^{3} \mathrm{H}_{4}{ }^{3}{ }^{3} \mathrm{H}_{6}$ centering at $800 \mathrm{~nm}$. The remarkable color change between $\mathrm{GdF}_{3}: \mathrm{Yb}^{3+}, \mathrm{Tm}^{3+}$ and GdOF: $\mathrm{Yb}^{3+}, \mathrm{Tm}^{3+}$ NCs could be attributed to the following reasons. First, the involving of oxygen defect states in GdOF host, which can increase non-radiative relaxation processes. ${ }^{43}$
For example, electrons on ${ }^{3} \mathrm{~F}_{2 / 3}$ can alternatively relax to the ${ }^{3} \mathrm{H}_{4}$ intermediate state via the multi-phonon depopulation process, generating ${ }^{3} \mathrm{H}_{4}-{ }^{3} \mathrm{H}_{6}(\sim 800 \mathrm{~nm})$ transition, instead of populating from ${ }^{3} \mathrm{~F}_{2 / 3}$ to ${ }^{1} \mathrm{G}_{4}$ level. Second, the crystal structure evolution from orthorhombic $\mathrm{GdF}_{3}$ to cubic GdOF results in shorter $\mathrm{Gd}^{3+}-\mathrm{Gd}^{3+}$ distance in cubic GdOF NCs (3.792 $\AA$ ) relative to that in orthorhombic $\mathrm{GdF}_{3} \mathrm{NCs}(3.884 \AA$ and $4.447 \AA$ ), as shown in Fig. 2(b and c). Consequently, the doping of $\mathrm{Yb}^{3+}$ and $\mathrm{Tm}^{3+}$ ions into the GdOF host structure by substitution of $\mathrm{Gd}^{3+}$ cation creates closer $\mathrm{Tm}^{3+}-\mathrm{Tm}^{3+}$ pairs than those in $\mathrm{GdF}_{3} \mathrm{NCs}$ lattices. The shorter distance between $\mathrm{Tm}^{3+}-\mathrm{Tm}^{3+}$ in GdOF NCs may improve the cross-relaxation processes $\left({ }^{3} \mathrm{H}_{6}+{ }^{3} \mathrm{H}_{4^{-}}{ }^{1} \mathrm{G}_{4}+\right.$ ${ }^{3} \mathrm{H}_{5},{ }^{3} \mathrm{H}_{6}+{ }^{3} \mathrm{~F}_{4}-{ }^{3} \mathrm{H}_{4}+{ }^{3} \mathrm{H}_{5}$ ), possibly leading to the increase of the ratios of $\mathrm{R} / \mathrm{B}$ (defines as the red emissions $\left({ }^{3} \mathrm{~F}_{3} /{ }^{3} \mathrm{H}_{4}-{ }^{3} \mathrm{H}_{6}\right.$ )/blue emissions $\left({ }^{1} \mathrm{D}_{2}-{ }^{3} \mathrm{H}_{6} /{ }^{3} \mathrm{~F}_{4},{ }^{1} \mathrm{G}_{4}-{ }^{3} \mathrm{H}_{6}\right)$ ratios) in GdOF: $\mathrm{Yb}^{3+}, \mathrm{Tm}^{3+}$ NCs. $^{44}$ Third, the size of UCNCs decreased from $15 \mathrm{~nm}$ to $2 \mathrm{~nm}$ with the crystal structure changed from $\mathrm{GdF}_{3}$ to $\mathrm{GdOF}$, leading to lower crystallinity and more surface defects, which increase the ratio of nonradiative decay of luminescence centers, leading the increase of $\mathrm{R} / \mathrm{B} .^{45}$

To better understand the multicolor tuning mechanism, the ratios $(\mathrm{R} / \mathrm{B})$ as a function of the excited power density are further studied, as shown in Fig. 4. In $\mathrm{GdF}_{3}: \mathrm{Yb}^{3+}, \mathrm{Tm}^{3+} \mathrm{NCs}$, the R/B ratios decreases gradually with the increase of the $980 \mathrm{~nm}$ excited power which is opposite to that observed in GdOF: $\mathrm{Yb}^{3+}, \mathrm{Tm}^{3+}$ NCs and traditional fluoride hosts. ${ }^{46}$ Generally, in some conventional fluoride samples (e.g. $\mathrm{NaYF}_{4}: \mathrm{Yb}, \mathrm{Er} / \mathrm{Tm}$, $\left.\mathrm{YF}_{3}: \mathrm{Yb}, \mathrm{Er} / \mathrm{Tm}\right)$, as the excitation density is high enough, the electron number of excited $\mathrm{Er}^{3+}$ or $\mathrm{Tm}^{3+}$ ions increases largely, inducing the increasing cross relaxation process, which effectively enhances the population at the ${ }^{4} \mathrm{~F}_{9 / 2}$ or ${ }^{1} \mathrm{G}_{4} /{ }^{3} \mathrm{H}_{4}$ energy

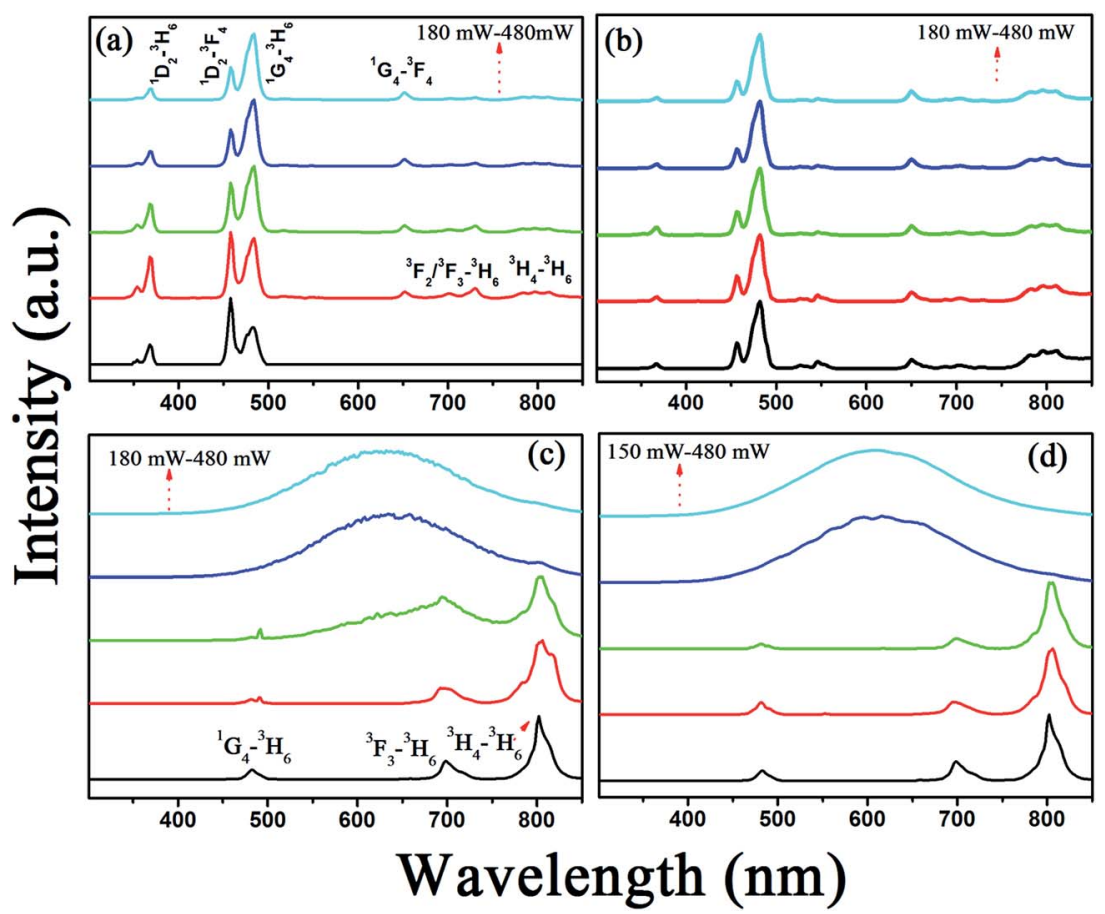

Fig. $3 \mathrm{UCL}$ spectra of $\mathrm{GdF}_{3}: \mathrm{Yb}^{3+}, \mathrm{Tm}^{3+}$ and GdOF:Yb ${ }^{3+}, \mathrm{Tm}^{3+} \mathrm{NCs}$ prepared at OM/ODE ratios of $4: 1,3: 2,2: 3$ and $1: 4$ with different $980 \mathrm{~nm}$ excitation power. 


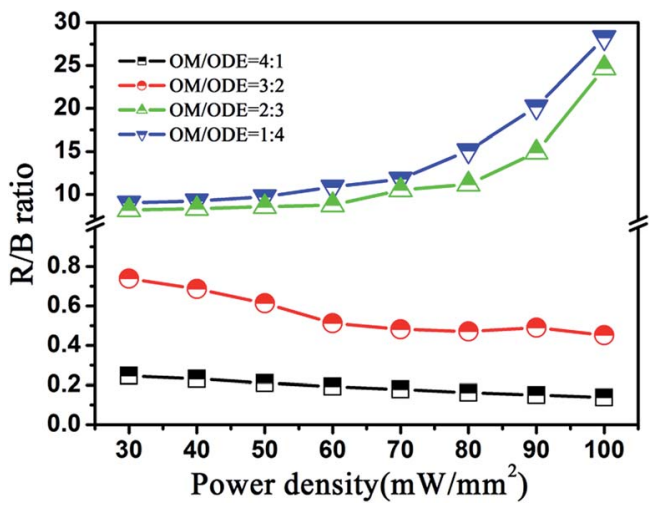

Fig. $4 \mathrm{R} / \mathrm{B}$ ratios of $\mathrm{GdF}_{3}: \mathrm{Yb}^{3+}, \mathrm{Tm}^{3+}$ and $\mathrm{GdOF}: \mathrm{Yb}^{3+}, \mathrm{Tm}^{3+} \mathrm{NCs}$ versus the $980 \mathrm{~nm}$ excitation power density.

level of $\mathrm{Er}^{3+}$ or $\mathrm{Tm}^{3+}$ ions. ${ }^{47}$ Instead, the decrease of $\mathrm{R} / \mathrm{B}$ ratios with excitation power in $\mathrm{GdF}_{3}: \mathrm{Yb}^{3+}, \mathrm{Tm}^{3+} \mathrm{NCs}$ could be attributed to the competition between linear decay and upconversion processes for the depletion of the intermediate excited states, which was theoretically described by Pollnau et al. ${ }^{48}$

\subsection{Upconversion broad band emission in GdOF: $\mathrm{Yb}^{3+}, \mathrm{Tm}^{3+}$ NCs}

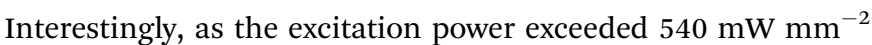
as shown in, a UC broad band emission in GdOF: $\mathrm{Yb}^{3+}, \mathrm{Tm}^{3+} \mathrm{NCs}$ ranging of 450-750 $\mathrm{nm}$ appears and the emission intensity dramatically increases with increasing the excitation power, the step of increasing the excitation power density is $30 \mathrm{~mW} \mathrm{~mm}^{-2}$ (Fig. 3(c) and (d)). The central wavelength of these UC broadband emissions locates around $600 \mathrm{~nm}(\sim 2.1 \mathrm{eV})$ and is independent of excitation power. The temperature measurement under the exposure of $980 \mathrm{~nm}$ light was achieved by burying the thermocouple thermometer into the powder plate samples in Fig. 5(a). The threshold temperature for the UC broad band emission of GdOF: $\mathrm{Yb}^{3+}, \mathrm{Tm}^{3+}$ NCs prepared at OM/ODE ratios of $2: 3$ and $1: 4$ were $475 \mathrm{~K}$ and $492 \mathrm{~K}$, which is much lower than the necessary temperature for generating sufficient blackbody radiation $(\sim 2500 \mathrm{~K}) .{ }^{49}$ Thus, the broadband do not come from the blackbody radiation. And we also exclude that the present UC broad band originates from the charge transfer transition of $\mathrm{Yb}^{2+}$ or $\mathrm{Yb}^{3+}$ ions, because the charge transfer emissions of $\mathrm{Yb}^{2+}$ and $\mathrm{Yb}^{3+}$ located at around $560 \mathrm{~nm}$ and $650 \mathrm{~nm}$ (ref. 50) (different from $600 \mathrm{~nm}$ ), the integral emission of broad band emission of GdOF: $\mathrm{Yb}^{3+}, \mathrm{Tm}^{3+}$ NCs was recorded every hour under the uninterrupted illumination of $980 \mathrm{~nm}(750 \mathrm{~mW})$, as shown in Fig. 5(b). Its intensity reduces less than $\sim 15 \%$ over $24 \mathrm{~h}$, which suggests that the broad band emission of GdO$\mathrm{F}: \mathrm{Yb}^{3+}, \mathrm{Tm}^{3+} \mathrm{NCs}$ has high photo-stability. In addition, the peak of UC broad band emission remains unaltered with increase of excitation power density and could be well fitted by a Gaussian function. Therefore, we deduce that UC broad band emission in GdOF: $\mathrm{Yb}^{3+}, \mathrm{Tm}^{3+} \mathrm{NCs}$ originates form the UCL of oxygen
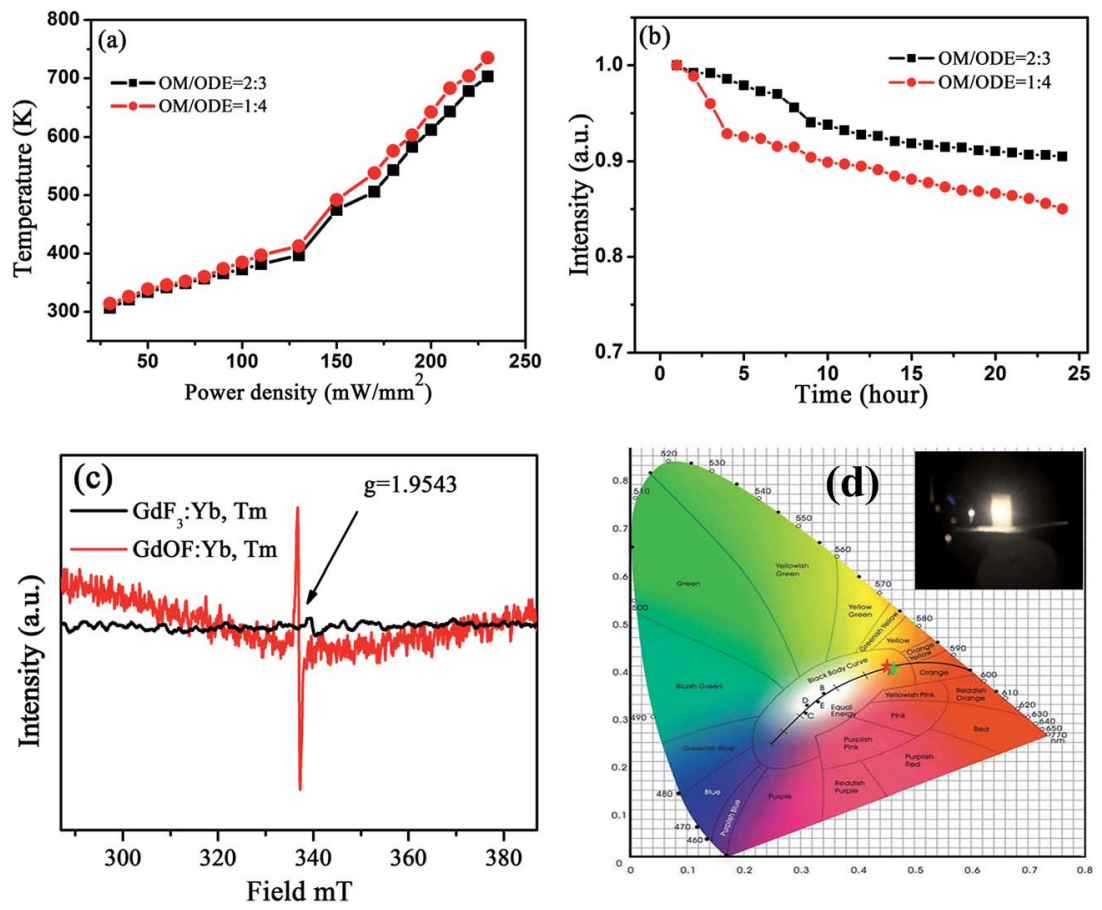

Fig. 5 (a) Sample temperature as a function of $980 \mathrm{~nm}$ excitation power density in GdOF:Yb ${ }^{3+}, \mathrm{Tm}^{3+} \mathrm{NCs}$ prepared at OM/ODE ratios of 2 : 3 and $1: 4$, (b) normalized integral intensity of $\mathrm{UC}$ broad band emissions in GdOF: $\mathrm{Yb}^{3+}, \mathrm{Tm}^{3+} \mathrm{NCs}$ in this measuring period of 24 hours under the uninterrupted illumination of $980 \mathrm{~nm}$ laser $(750 \mathrm{~mW})$, (c) EPR spectra of $\mathrm{GdF}_{3}: \mathrm{Yb}^{3+}, \mathrm{Tm}^{3+}$ and GdOF:Yb ${ }^{3+}, \mathrm{Tm}^{3+} \mathrm{NCs}^{3}$ at room temperature prepared at OM/ODE ratio of $4: 1$ and $1: 4$, (d) CIE chromaticity coordinates diagram of GdOF:Yb ${ }^{3+}, \mathrm{Tm}^{3+} \mathrm{NCs}^{3}$ prepared at OM/ODE ratios of $2: 3$ and $1: 4$ under the excitation power of $750 \mathrm{~mW}$ from a $980 \mathrm{~nm}$ laser diode. Inset is the digital photograph of broadband emission of GdOF: $\mathrm{Yb}^{3+}, \mathrm{Tm}^{3+}$ 
defects. ${ }^{51}$ In order to further prove this, the electron paramagnetic resonance (EPR) spectra of $\mathrm{GdF}_{3}: \mathrm{Yb}^{3+}, \mathrm{Tm}^{3+} \mathrm{NCs}$ and GdOF: $\mathrm{Yb}^{3+}, \mathrm{Tm}^{3+} \mathrm{NCs}$ are recorded in Fig. 5(c). No EPR signal can be distinguished in $\mathrm{GdF}_{3}: \mathrm{Yb}^{3+}, \mathrm{Tm}^{3+} \mathrm{NCs}$, while in GdOF: $\mathrm{Yb}^{3+}, \mathrm{Tm}^{3+} \mathrm{NCs}$, a EPR signal is detected in the range of 0$800 \mathrm{mT}$ with $g$ factor of $\sim 1.9543$. In general, when the actual measured $g$ factor is lower than the free electron $g$ factor $\left(g_{\text {free }}=\right.$ 2.0023), the EPR signal represents the electron trap..$^{52}$ Accordingly, the EPR signal in GdOF: $\mathrm{Yb}^{3+}, \mathrm{Tm}^{3+} \mathrm{NCs}$ should be assigned to the oxygen defects. Taken all together, as the excitation power is high enough, the temperature of GdO$\mathrm{F}: \mathrm{Yb}^{3+}, \mathrm{Tm}^{3+} \mathrm{NCs}$ samples increases considerably, leading to the cross relaxation $\left({ }^{3} \mathrm{~F}_{2 / 3}+{ }^{3} \mathrm{~F}_{2 / 3}-{ }^{1} \mathrm{G}_{4}+{ }^{3} \mathrm{H}_{5}\right)$ exacerbating (the superstrong power-dependence of the slopes (more than 10) further implies its happening, as shown in Fig. 7(c and d)). Then, most

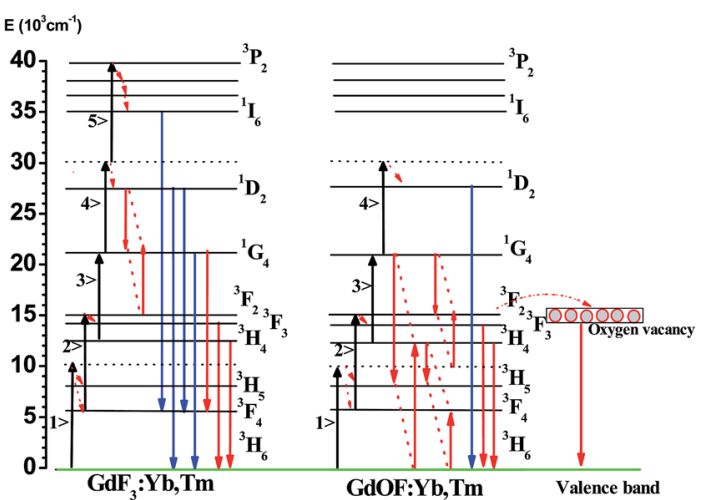

Fig. 6 Schematic of UCL populations and UC broadband mechanisms in $\mathrm{Yb}^{3+}, \mathrm{Tm}^{3+}$ co-doped $\mathrm{GdF}_{3}$ and GdOF samples under $980 \mathrm{~nm}$ excitation. of the electrons on ${ }^{3} \mathrm{~F}_{2}$ might be captured by the oxygen vacancy states through the tunneling effect. The UC multicolor population and UC broad band emission mechanism in $\mathrm{GdF}_{3}$ :$\mathrm{Yb}^{3+}, \mathrm{Tm}^{3+}$ and GdOF: $\mathrm{Yb}^{3+}, \mathrm{Tm}^{3+}$ NCs are presented in Fig. 6. Furthermore, we calculates the International Commission on Illumination (CIE) coordinates of the broad band emission in GdOF: $\mathrm{Yb}^{3+}, \mathrm{Tm}^{3+} \mathrm{NCs}$, which are $(0.455,0.406)$ and $(0.466,0.403)$ respectively, which both are located at white light region (shown in Fig. 5(d)). The inset of Fig. 5(d) shows a digital photograph of UC broad band emission of GdOF: $\mathrm{Yb}^{3+}, \mathrm{Tm}^{3+}$ excited $980 \mathrm{~nm}$ laser $(750 \mathrm{~mW})$. The bright white light can be seen clearly from the sample and the brightness is $5.3 \times 10^{4} \mathrm{~cd} \mathrm{~m}^{-2}$, which has potential applications in white-light illumination. ${ }^{53}$

\subsection{Power-dependence of UCL}

The visible output power intensity $\left(I_{\mathrm{V}}\right)$ is proportional to power $(n)$ of the infrared excitation $\left(I_{\mathrm{IR}}\right)$ power if the saturation effect can be neglected: ${ }^{54}$

$$
I_{\mathrm{V}} \propto I_{\mathrm{IR}}^{n}
$$

where $n$ is the number of IR photons absorbed per visible photon emitted. The $\ln$-ln plots of the emission intensity in $\mathrm{GdF}_{3}$ :$\mathrm{Yb}^{3+}, \mathrm{Tm}^{3+}$ and GdOF: $\mathrm{Yb}^{3+}, \mathrm{Tm}^{3+} \mathrm{NCs}$ as a function of excitation power for all the emissions levels are listed in Fig. 7. It is observed that the slopes of ${ }^{1} \mathrm{D}_{2}-{ }^{3} \mathrm{H}_{6},{ }^{1} \mathrm{G}_{4}-{ }^{3} \mathrm{H}_{6},{ }^{3} \mathrm{H}_{4}-{ }^{3} \mathrm{H}_{6}$ in $\mathrm{GdF}_{3}: \mathrm{Yb}^{3+}, \mathrm{Tm}^{3+} \mathrm{NCs}$ and ${ }^{1} \mathrm{G}_{4}-{ }^{3} \mathrm{H}_{6},{ }^{3} \mathrm{~F}_{3}-{ }^{3} \mathrm{H}_{6},{ }^{3} \mathrm{H}_{4}-{ }^{3} \mathrm{H}_{6}$ in GdO$\mathrm{F}: \mathrm{Yb}^{3+}, \mathrm{Tm}^{3+} \mathrm{NCs}$ are lower in different degree in comparison to the actual phonon numbers, and it is mainly due to the so-called saturation effect. The values of $n$ for both the blue $\left({ }^{1} \mathrm{G}_{4}-{ }^{3} \mathrm{H}_{6}\right)$ and red $\left({ }^{3} \mathrm{~F}_{3},{ }^{3} \mathrm{H}_{4}-{ }^{3} \mathrm{H}_{6}\right)$ emissions of $\mathrm{Tm}$ ions at the relatively low excitation power in the $\mathrm{GdF}_{3}: \mathrm{Yb}^{3+}, \mathrm{Tm}^{3+} \mathrm{NCs}$ is larger than that in

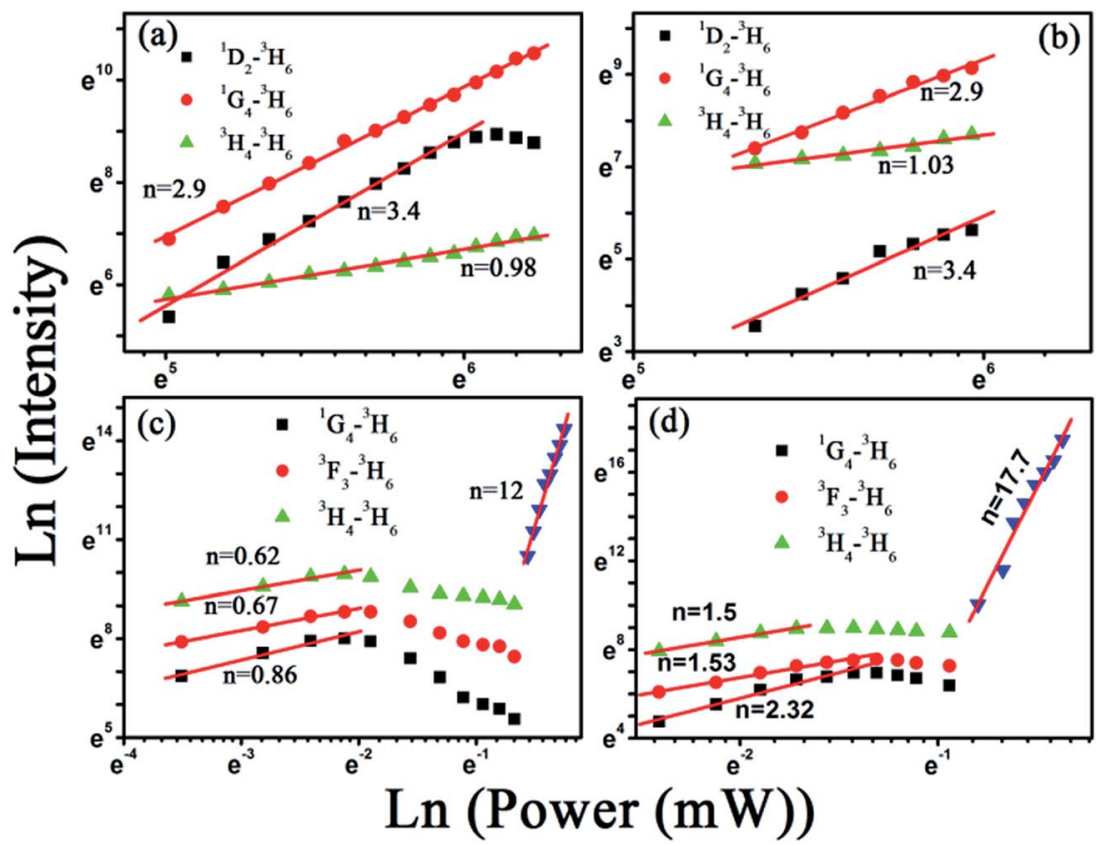

Fig. 7 Plot (ln-ln) of emission intensity versus excitation power in (a and b) GdF $\mathrm{Yb}^{3+}, \mathrm{Tm}^{3+}$ and (c and d) GdOF:Yb ${ }^{3+}, \mathrm{Tm}^{3+} \mathrm{NCs}^{3}$ prepared at different $O M / O D E$ ratios of $4: 1,3: 2,2: 3$ and $1: 4$, respectively. 
GdOF: $\mathrm{Yb}^{3+}, \mathrm{Tm}^{3+}$ NCs. In addition, in the $\mathrm{GdF}_{3}: \mathrm{Yb}^{3+}, \mathrm{Tm}^{3+} \mathrm{NCs}$, the UCL intensity increases continuously in the studied range, while in the GdOF: $\mathrm{Yb}^{3+}, \mathrm{Tm}^{3+} \mathrm{NCs}$, the quenching of UCL appears at a certain excitation power, which should be attributed to the thermal effect. Thermal effect is seriously affected by the phonon energy of the host. Because the phonon energy of GdOF $\left(550 \mathrm{~cm}^{-1}\right)$ is larger than that of $\operatorname{GdF}_{3}\left(320 \mathrm{~cm}^{-1}\right)$, the thermal effect would be smaller in $\mathrm{GdF}_{3}$ NCs under the same power density excitation, leading to the smaller slopes in GdO$\mathrm{F}: \mathrm{Yb}^{3+}, \mathrm{Tm}^{3+}$. We also observed that the slope of ${ }^{3} \mathrm{H}_{4}{ }^{-}{ }^{3} \mathrm{H}_{6}$ transition is $\sim 1$ in $\mathrm{GdF}_{3}: \mathrm{Yb}^{3+}, \mathrm{Tm}^{3+} \mathrm{NCs}$ (shown in Fig. 7(a and b)). In the UC population process, if the linear decay is dominant, $I_{\mathrm{V}} \propto$ $I_{\mathrm{IR}}{ }^{n}$, otherwise, the UC is dominant, $I_{\mathrm{V}} \propto I_{\mathrm{IR}} \cdot{ }^{41}$ Therefore the UC is the dominant depletion mechanism of ${ }^{3} \mathrm{H}_{4}$ level in $\mathrm{GdF}_{3}$ :$\mathrm{Yb}^{3+}, \mathrm{Tm}^{3+} \mathrm{NCs}$, which is also in consistent with the decrease of $\mathrm{R} / \mathrm{B}$ ratios with the increase of $980 \mathrm{~nm}$ excitation power (Fig. 4). Particularly, in Fig. 7(c and d), as the UC broadband emission appears, the UCL intensity increases dramatically with the increasing excitation power along with the slope reaching as high as 12 and 17.7, respectively. The super-strong powerdependence of the slopes (more than 10) implies that the UC broad band in GdOF: $\mathrm{Yb}^{3+}, \mathrm{Tm}^{3+} \mathrm{NCs}$ might originate from a photon avalanche population process, instead of a traditional multiple-photon population process. Compared to the well known NaYF: $\mathrm{Yb}^{3+}, \mathrm{Tm}^{3+}\left(\mathrm{Er}^{3+}\right)$ nanocrystals (several nanometers) encountering the intensifying cross-relaxation or saturation effect under high power $980 \mathrm{~nm}$ excitation, UC broad band emission of GdOF: $\mathrm{Yb}^{3+}, \mathrm{Tm}^{3+}$ has better performance instead, which has the potential applications in a white light LED.

\subsection{Dynamic processes in $\mathrm{GdF}_{3}: \mathrm{Yb}^{3+}, \mathrm{Tm}^{3+}$ and GdOF: $\mathbf{Y b}^{3+}, \mathbf{T m}^{3+}$ NCs}

Fig. 8 shows the UCL dynamic curves of ${ }^{1} \mathrm{G}_{4}{ }^{3}{ }^{3} \mathrm{H}_{6}$ transition in $\mathrm{GdF}_{3}: \mathrm{Yb}^{3+}, \mathrm{Tm}^{3+}$ and GdOF: $\mathrm{Yb}^{3+}, \mathrm{Tm}^{3+} \mathrm{NCs}$ under $980 \mathrm{~nm}$ excitation with different ratios of OM/ODE, which can be well fitted

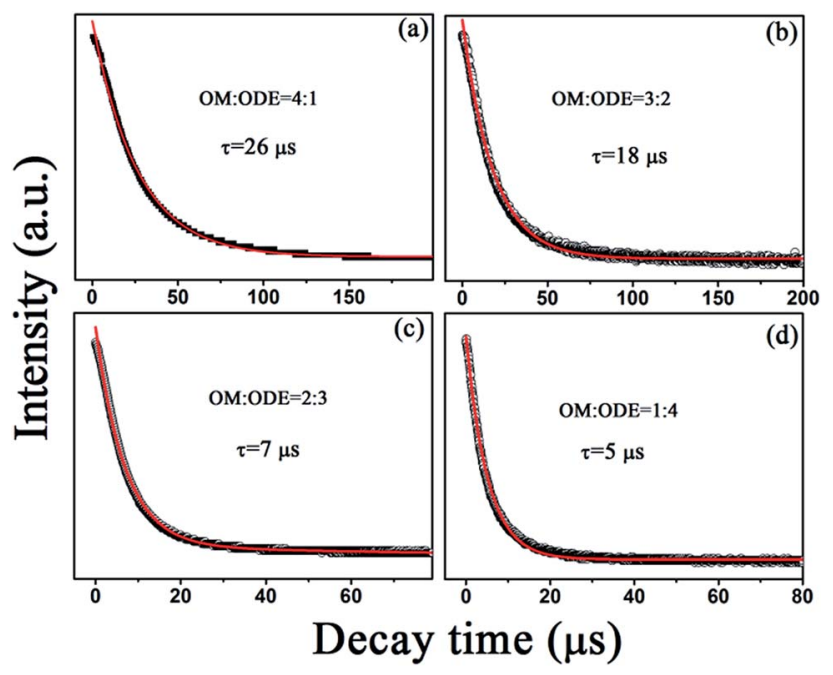

Fig. $8 \mathrm{UCL}$ decay dynamics curves of the ${ }^{1} \mathrm{G}_{4}-{ }^{3} \mathrm{H}_{6}$ transition at $480 \mathrm{~nm}$ of $\mathrm{Tm}^{3+}$ ions in ( $\mathrm{a}$ and b) $\mathrm{GdF}_{3}: \mathrm{Yb}^{3+}, \mathrm{Tm}^{3+}$ and (c and d) GdOF: $\mathrm{Yb}^{3+}, \mathrm{Tm}^{3+} \mathrm{NCs}$ prepared at different OM/ODE ratios of $4: 1$, $3: 2,2: 3$ and $1: 4$ under the $980 \mathrm{~nm}$ excitation. to a single exponential function. It can be clearly seen that the decay time constants reduce from 26 to $5 \mu$ s with the change of the ratios of OM/ODE from $4: 1$ to $1: 4$, which can be attributed to the cooperative effect of the particle size, crystal phase, phonon energy and defects state. Firstly, as the particle size decreases, the number of detects and the large phonon bonds on the surface of the NCs increase due to the increase of the volume to surface ratio, leading the nonradiative relaxations (such as ${ }^{1} \mathrm{D}_{2}-{ }^{1} \mathrm{G}_{4}$ and ${ }^{1} \mathrm{G}_{4}-{ }^{3} \mathrm{~F}_{2}$ ) to happen easily. Secondly, as known, in GdOF: $\mathrm{Yb}^{3+}, \mathrm{Tm}^{3+} \mathrm{NCs}$, the distance among $\mathrm{Tm}^{3+}$ ions decreases relative to that in $\mathrm{GdF}_{3}: \mathrm{Yb}^{3+}, \mathrm{Tm}^{3+} \mathrm{NCs}$, so the crossrelaxation process (such as ${ }^{1} \mathrm{G}_{4}+{ }^{3} \mathrm{H}_{4}-{ }^{3} \mathrm{~F}_{4}+{ }^{1} \mathrm{D}_{2},{ }^{3} \mathrm{~F}_{2 / 3}+{ }^{3} \mathrm{~F}_{2 /}$ ${ }_{3}^{-1} \mathrm{G}_{4}+{ }^{3} \mathrm{H}_{5}$ ) among $\mathrm{Tm}^{3+}$ ions should be intensified in the UC population process. Thirdly, the larger phonon energy (550 $\mathrm{cm}^{-1}$ ) of GdOF: $\mathrm{Yb}^{3+}, \mathrm{Tm}^{3+}$ NCs leads the increase of the nonradiative relaxation processes via multiphonon assistant. The above factors result in the increase of nonradiative relaxation processes from excited states $\left(\right.$ e.g. ${ }^{1} \mathrm{D}_{2},{ }^{1} \mathrm{G}_{4},{ }^{3} \mathrm{~F}_{4}$ and ${ }^{3} \mathrm{H}_{4}$ for $\mathrm{Tm}^{3+}$ ions) to defect states and/or large phonon bonds, leading to the decreasing of the decay time constants as well as the tuning of UC multicolor emissions.

\section{Conclusions}

In this research, we fabricated rhombic $\mathrm{GdF}_{3}: \mathrm{Yb}^{3+}, \mathrm{Tm}^{3+}$ and spherical GdOF: $\mathrm{Yb}^{3+}, \mathrm{Tm}^{3+}$ UCNCs using the thermolysis method. The effect of OM/ODE ratios on size, shape and multicolor tuning of lanthanide-ion doped UCNCs was studied in detail. The experimental results can be summarized as following. First, the UC emission color change from blue to red was observed with the transform of the crystalline phase from orthorhombic $\mathrm{GdF}_{3}$ to cubic GdOF NCs, which was mainly attributed to cooperative effect among crystal phase structure and size of UCNCs. Second, UC broadband emissions with super power-dependent lopes are observed in GdOF: $\mathrm{Yb}^{3+}, \mathrm{Tm}^{3+}$ under $980 \mathrm{~nm}$ laser illumination with high excitation power. Their origin could be oxygen vacancies, being accompanied by a photon avalanche population process. These UCNCs with broadband multi-color emissions are expected to find their applications in multi-color bio-imaging, white-light emitting diodes, and multiplexed cellular labeling.

\section{Acknowledgements}

This work was supported by National Natural Science Foundation of China (Grant no. 11504188, 11504131, 51374132), Natural Science Foundation of Henan Province (Grant no. U1504626), Science Foundation of Henan department of education of China (Grant no. 15A140011), the Open Fund of the State Key Laboratory On Integrated Optoelectronics (Grant no. 2015IOSKL KF31).

\section{References}

1 F. Auzel, Chem. Rev., 2004, 104, 139.

2 W. Zheng, P. Huang, D. T. Tu, E. Ma, H. M. Zhu and X. Y. Chen, Chem. Soc. Rev., 2015, 44, 1379. 
3 R. R. Deng, F. Qin, R. F. Chen, W. Huang, M. H. Hong and X. G. Liu, Nat. Nanotechnol., 2015, 10, 237-242.

4 X. Zhang, P. P. Yang, Y. L. Dai, P. A. Ma, X. J. Li, Z. Y. Cheng, Z. Y. Hou, X. J. Kang, C. X. Li and J. Lin, Adv. Funct. Mater., 2013, 23, 4067-4078.

5 X. X. Hu, T. Wei, J. Wang, Z. E. Liu, X. Y. Li, B. H. Zhang, Z. H. Li, L. L. Li and Q. Yuan, Anal. Chem., 2014, 86, 10484-10491.

6 X. Y. Huang, S. Y. Han, W. Huang and X. G. Liu, Chem. Soc. Rev., 2013, 42, 173.

7 B. Zhou, B. Y. Shi, D. Y. Jin and X. G. Liu, Nat. Nanotechnol., 2015, 10, 924-936.

8 Y. Q. Lu, J. B. Zhao, R. Zhang, Y. J. Liu, D. M. Liu, E. M. Goldys, X. S. Yang, P. Xi, A. Sunna, J. Lu, Y. Shi, R. C. Leif, Y. J. Huo, J. Shen, J. A. Piper, J. P. Robinson and D. Y. Jin, Nat. Photonics, 2014, 8, 32-36.

9 S. Lu, D. T. Tu, P. Hu, J. Xu, R. F. Li, M. Wang, Z. Chen, M. D. Huang and X. Y. Chen, Angew. Chem., Int. Ed., 2015, 54, 7915-7919.

10 J. B. Zhao, D. Y. Jin, E. P. Schartner, Y. Q. Lu, Y. J. Liu, A. V. Zvyagin, L. X. Zhang, J. M. Dawes, P. Xi, J. A. Piper, E. M. Goldys and T. M. Monro, Nat. Nanotechnol., 2013, 8, 729.

11 X. M. Li, Z. Z. Guo, T. C. Zhao, Y. Lu, L. Zhou, D. Y. Zhao and F. Zhang, Angew. Chem., Int. Ed., 2016, 55, 2464-2469.

12 O. Ehlert, R. Thomann, M. Darbandi and T. Nann, ACS Nano, 2008, 2, 120.

13 H. X. Mai, Y. W. Zhang, L. D. Sun and C. H. Yan, J. Phys. Chem. C, 2007, 111, 13721-13729.

14 A. Nadort, J. B. Zhao and E. M. Goldys, Nanoscale, 2016, 8, 13099.

15 J. Wang, H. W. Song, W. Xu, B. Dong, S. Xu, B. T. Chen, W. Yu and S. Zhang, Nanoscale, 2013, 5, 3412.

16 A. Punjabi, X. Wu, A. Tokatli-Apollon, M. El-Rifai, H. Lee, Y. W. Zhang, C. Wang, Z. Liu, E. M. Chan, C. Y. Duan and G. Han, ACS Nano, 2014, 8, 10621-10630.

17 X. Teng, Y. H. Zhu, W. Wei, S. C. Wang, J. F. Huang, R. Naccache, W. B. Hu, A. I. YoongTok, Y. Han, Q. C. Zhang, Q. L. Fan, W. Huang, J. A. Capobianco and L. Huang, J. Am. Chem. Soc., 2012, 134, 8340-8343.

18 Z. E. Liu, J. Wang, Y. Li, X. X. Hu, J. W. Yin, Y. Q. Peng, Z. H. Li, Y. W. Li, B. M. Li and Q. Yuan, ACS Appl. Mater. Interfaces, 2015, 7, 19416-19423.

19 F. Wang, R. R. Deng, J. Wang, Q. X. Wang, Y. Han, H. M. Zhu, X. Y. Chen and X. G. Liu, Nat. Mater., 2011, 10, 968-973.

20 J. F. Ren, G. H. Jia, Y. Y. Guo, A. X. Wang and S. Q. Xu, J. Phys. Chem. C, 2016, 120, 1342-1351.

21 J. Wang, H. W. Song, W. Xu, B. Dong, S. Xu, B. T. Chen, W. Yu and S. Zhang, Nanoscale, 2013, 5, 3412.

22 Y. Zhang, X. J. Li, D. L. Geng, M. M. Shang, H. Z. Lian, Z. Y. Cheng and J. Lin, CrystEngComm, 2014, 16, 2196.

23 X. M. Li, F. Zhang and D. Y. Zhao, Chem. Soc. Rev., 2015, 44, 1346.

24 I. F. Li, C. H. Su, H. S. Sheu, H. C. Chiu, Y. W. Lo, W. T. Lin, J. H. Chen and C. S. Yeh, Adv. Funct. Mater., 2008, 18, 766.
25 J. Zhou, M. X. Yu, Y. Sun, X. Z. Zhang, X. J. Zhu, Z. H. Wu, D. M. Wu and F. Y. Li, Biomaterials, 2011, 32, 1148.

26 B. K. Gupta, V. Rathee, T. N. Narayanan, P. Thanikaivelan, A. Saha, Govind, S. P. Singh, V. Shanker, A. A. Marti and P. M. Ajaya, Small, 2011, 13, 1767.

27 Y. P. Du, Y. W. Zhang, L. D. Sun and C. H. Yan, J. Phys. Chem. $C, 2008,112,405-415$.

28 M. M. Shang, G. G. Li, X. J. Kang, D. M. Yang, D. L. Geng, C. Peng, Z. Y. Cheng, H. Z. Lian and J. Lin, Dalton Trans., 2012, 41, 5571.

29 L. Tao, W. Xu, Y. S. Zhu, L. Xu, H. C. Zhu, Y. X. Liu, S. Xu, P. W. Zhou and H. W. Song, J. Mater. Chem. C, 2014, 2, 4186.

30 Q. Ju, Y. S. Liu, D. T. Tu, H. M. Zhu, R. F. Li and X. Y. Chen, Chem.-Eur. J., 2011, 17, 8549-8554.

31 J. E. Roberts, J. Am. Chem. Soc., 1961, 83, 1087.

32 Y. F. Wang, L. D. Sun, J. W. Xiao, W. Feng, J. C. Zhou, J. Shen and C. H. Yan, Chem.-Eur. J., 2012, 18, 5558-5564.

33 G. Q. Chai, G. P. Dong, J. R. Qiu, Q. Y. Zhang and Z. M. Yang, Sci. Rep., 2013, 3, 1598.

34 E. Talik, P. Zajdel, A. Guzik, D. Skrzypek, L. Lipńska and M. Michalska, J. Alloys Compd., 2014, 616, 556-568.

35 I. Levin, Q. Z. Huang, L. P. Cook and W. Wong-Ng, Eur. J. Inorg. Chem., 2005, 87, 91.

36 R. Q. Li, N. N. Zhang, L. L. Li, Y. M. Liang, Y. L. Liu and S. C. Gan, New J. Chem., 2015, 39, 7019.

37 X. Sun, Y. W. Zhang, Y. P. Du, Z. G. Yan, R. Si, L. P. You and C. H. Yan, Chem.-Eur. J., 2007, 13, 2320-2332.

38 M. Haase and H. Schäfer, Angew. Chem., Int. Ed., 2011, 50, 5808-5829.

39 D. M. Liu, X. X. Xu, Y. Du, X. Qin, Y. H. Zhang, C. S. Ma, S. H. Wen, W. Ren, E. M. Goldys, J. A. Piper, S. X. Dou, X. G. Liu and D. Y. Jin, Nat. Commun., 2016, 7, 10254.

40 Y. F. Wang, W. Xu, S. B. Cui, S. Xu, Z. Yin, H. W. Song, P. W. Zhou, X. Y. Liu, L. Xu and H. N. Cui, Nanoscale, 2015, 7, 1363.

41 C. Jacinto, M. V. D. Vermelho, E. A. Gouveia and M. T. Araujo, Appl. Phys. Lett., 2007, 91, 071102.

42 X. Bai, D. Li, Q. Liu, B. Dong, S. Xu and H. W. Song, J. Mater. Chem., 2012, 22, 24698.

43 C. M. Zhang and J. Lin, Chem. Soc. Rev., 2012, 41, 7938-7961. 44 D. Li, B. Dong, X. Bai, Y. Wang and H. W. Song, J. Phys. Chem. C, 2010, 114, 8219-8226.

45 W. B. Niu, S. L. Wu and S. F. Zhang, J. Mater. Chem., 2011, 21, 10894-10902.

46 W. Yu, W. Xu, H. W. Song and S. Zhang, Dalton Trans., 2014, 43, 6139-6147.

47 C. Y. Liu, Z. Y. Gao, J. F. Zeng, Y. Hou, F. Fang, Y. L. Li, R. R. Qiao, L. Shen, H. Lei, W. S. Yang and M. Y. Gao, ACS Nano, 2013, 7, 7227.

48 M. Pollnau, D. R. Gamelin, S. R. Lüthi, H. U. Güdel and M. P. Hehlen, Phys. Rev. B: Condens. Matter Mater. Phys., 2000, 61, 3337.

49 S. Redmond, S. C. Rand, X. L. Ruan and M. Kaviany, J. Appl. Phys., 2004, 95, 4069.

50 W. Strek, L. Marciniak, A. Bednarkiewicz, A. Lukowiak, R. Wiglusz and D. Hreniak, Opt. Express, 2011, 19, 14083. 
51 Y. S. Zhu, W. Xu, S. B. Cui, M. Liu, C. Lu, H. W. Song and D. H. Kim, J. Mater. Chem. C, 2016, 4, 331.

52 Y. Liu, S. L. Wan and X. G. Li, J. Phys.: Condens. Matter, 2007, 19, 196213.
53 X. Bai, G. Caputo, Z. D. Hao, V. T. Freitas, J. H. Zhang, R. L. Longo, O. L. Malta, R. A. S. Ferreira and N. Pinna, Nat. Commun., 2014, 5, 5702.

54 Z. Wang, J. Feng, M. Pang, S. H. Pan and H. J. Zhang, Dalton Trans., 2013, 42, 12101. 